\title{
ANTERIOR SKULL BASE ANALYSIS FROM CORONAL AND RECONSTRUCTED COMPUTED TOMOGRAPHY: RADIO-ANATOMICAL STUDY
}

\author{
Bhima Neupane, ${ }^{1}$ Phanindra Prasad Poudel, ${ }^{1}$ Prakash Sharma, ${ }^{2}$ Krishna Koirala, ${ }^{3}$ \\ Brihaspati Sigdel ${ }^{4}$
}

${ }^{1}$ Department of Anatomy, ${ }^{2}$ Department of Radiodiagnosis and Imaging, ${ }^{3}$ Department of Otolaryngology, Manipal College of Medical Sciences, and Manipal Teaching Hospital, ${ }^{4}$ Department of Otolaryngology, Gandaki Medical College, Pokhara, Nepal

\section{ABSTRACT}

Endoscopic sinus and skull base Surgery has gained significant improvement widely all over the world. A computerized tomography (CT) scan provides a detailed anatomy of the skull base especially the bone framework. This study aims to analyze the fixed anatomical bony landmarks of the anterior skull base through coronal and reconstructed CT in the context of the Nepalese population and guide the surgeon to perform endoscopic sinus and skull base surgery safely. This Prospective study includes 70 Computerized Tomography scans of Paranasal sinuses. The different measurement from nasal floor to skull base was taken in coronal and reformatted sagittal CT scan. Mean, standard deviation, minimum and maximum values were analyzed using descriptive statistics. Student T-test was applied to compare between right and left side.This study includes 75 patients between 18 to 77 years. The measurement from nasal floor to the cribriform plate and ethmoidal roof in right and left side were, mean \pm SD $(47 \pm 4.1,45.3 \pm 4.3$, $47.9 \pm 5.1$, and $49 \pm 8.5 \mathrm{~mm}$ ) respectively. Mean Take off angle at the cribriform plate was 43.9 $\pm 10.9^{\circ}$ on right side and $43 \pm 9.4^{\circ}$ on the left side. The distance from the nasal spine to the skull base (mean \pm SD) at nasofrontal recess, bulla ethmoidalis, and the junction of sphenoethmoid levels at right sides were $51.5 \pm 4.7,52.9 \pm 4.1$, and $61.2 \pm 4.7$ little higher at left side. This study provides a detailed analysis of the anterior skull base in coronal and sagittal CT scans which helps to reduces complications.

\section{KEYWORDS}

Anterior skull base, Cribriform plate, Nasal floor.

Received on: June 22, 2021

Accepted for publication: October 23, 2021

\section{CORRESPONDING AUTHOR}

Dr. Bhima Neupane,

Lecturer,

Department of Anatomy

Manipal College of Medical Sciences,

Pokhara, Nepal

Email: bhimasigdel@gmail.com

Orcid No: https://orcid.org/0000-0002-7647-4099

DOI: https://doi.org/10.3126/nmcj.v23i4.42216 


\section{INTRODUCTION}

Endoscopic resection of skull base surgery had gained significant improvement widely all over the world. ${ }^{1}$ After the development of Hopkin rod endoscopic high-definition cameras, such surgery has become more feasible and accurate. A computerized tomography scan is a helpful tool in detecting important anatomical bony landmarks and helps in further planning and navigating the surgery accurately to minimize complications. $^{2}$ It also provides important information about location and extension of lesions to allow better surgical planning and patient management. As the bones adjacent to the anterior skull base are small and thin which can be damaged easily during surgery further leading to disorientation in primary and revision surgery. ${ }^{3}$

Fixed anatomical bony landmarks allow safe dissection and complete disease removal. The nasal floor, choane, maxillary sinus roof, cribriform plate, skull base, Plannum, and orbital wall are the fixed anatomic features that we have to seek during endoscopic surgery. It is important to remember that the morphometric anatomy of the ethmoid roof can vary widely among the population. ${ }^{4}$ Most of the studies were performed in western countries, it is important to find out measurement among different fixed landmark in our population.

The main purpose of our study is to analyze the fixed anatomical landmarks of the anterior skull base through coronal and reconstructed CT in the context of the Nepalese population and guide the surgeon to perform endoscopic sinus and skull base surgery safely.

\section{MATERIALS AND METHODS}

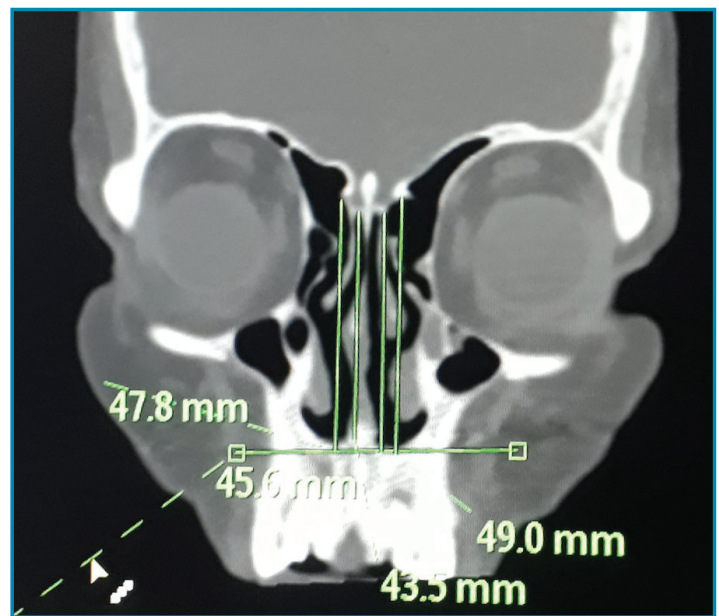

Fig. 1: A Coronal CT scan showing distance from nasal floor to cribriform plate and ethmoid roof
This Prospective study was conducted in the Manipal College of Medical Sciences and Teaching Hospital, Pokhara, Nepal from September 2020 to May 2021. Data was collected from the Department of Radiodiagnosis and Imaging with informed consent from the patient. Total $70 \mathrm{CT}$ scans of paranasal sinus both coronal, and reconstructed sagittal images were analyzed. Sampling was performed by probability method. Sample size (n) was calculated by formula $\mathrm{n}=\mathrm{Za}^{2} \sigma^{2} / \mathrm{e}^{2}$ Where $\mathrm{a}^{2}$ $=95 \%$ level of significance, where $Z=1.96$ ( $\mathrm{z}=$ the value of the standard variate at a given confidence level and it is 1.96 for a $95 \%$ confidence level), e=1-3 (absolute error), $\sigma=$ 4.24 (standard deviation). The total sample

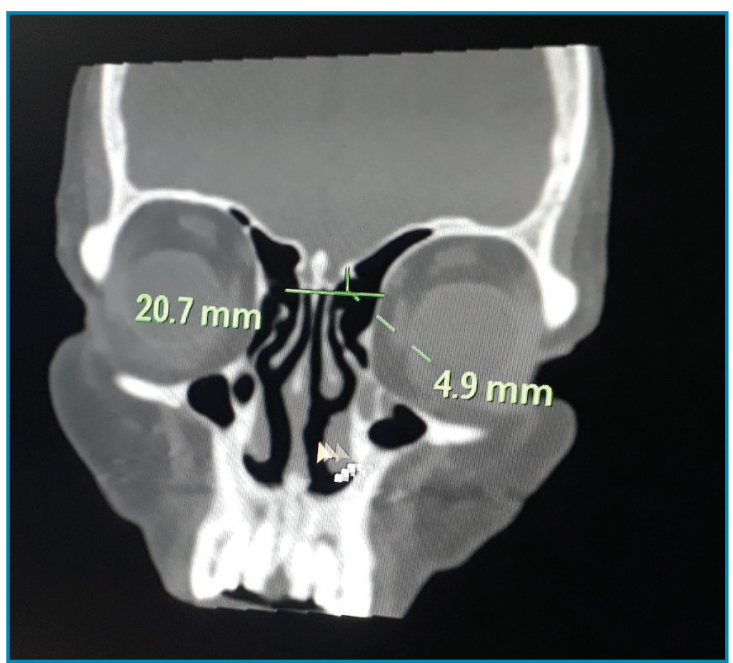

Fig. 2: CT scan paranasal sinuses coronal view showing left Foveal height.

size calculated was 70 . CT of paranasal sinus above age 18 years performed for chronic rhinosinusitis, nasal polyp, benign tumor, sinus type headache, facial pain, and head and spine related disease and injury cases who needed Paranasal sinus CT without distorted anatomy were included. Patients who had undergone surgery for paranasal sinus, and malignant disease involving anterior skull base or nasal polyps that obscured anatomical features were excluded from the study.

Routine CT examination was performed on the coronal plane with 3-mm slice thickness and no interslice gap was analyzed starting from the anterior border of the frontal sinus to the clivus. From these images, $1 \mathrm{~mm}$ thickness coronal (exactly perpendicular to the hard palate), and 0.5-mm thickness sagittal oblique reconstructions were obtained. Sagittal oblique images were created as slices, passing medially from the inferior contour of the bony nasal septum and laterally from the ethmoid bulla 


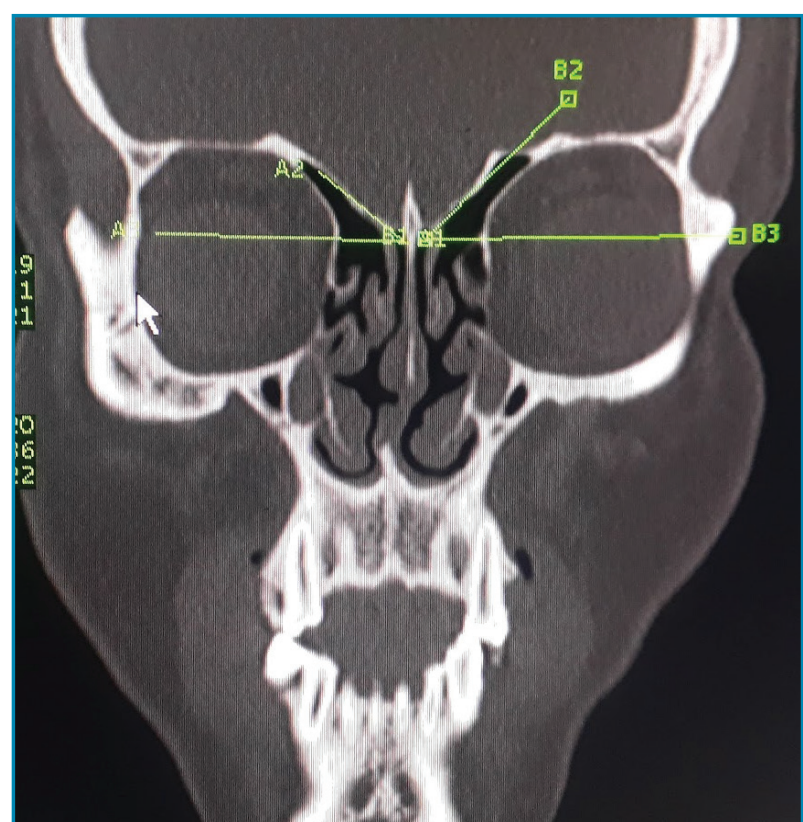

Fig. 3: Take-off angle of the ethmoid roof from horizontal plane of CT scan paranasal sinuses coronal view.

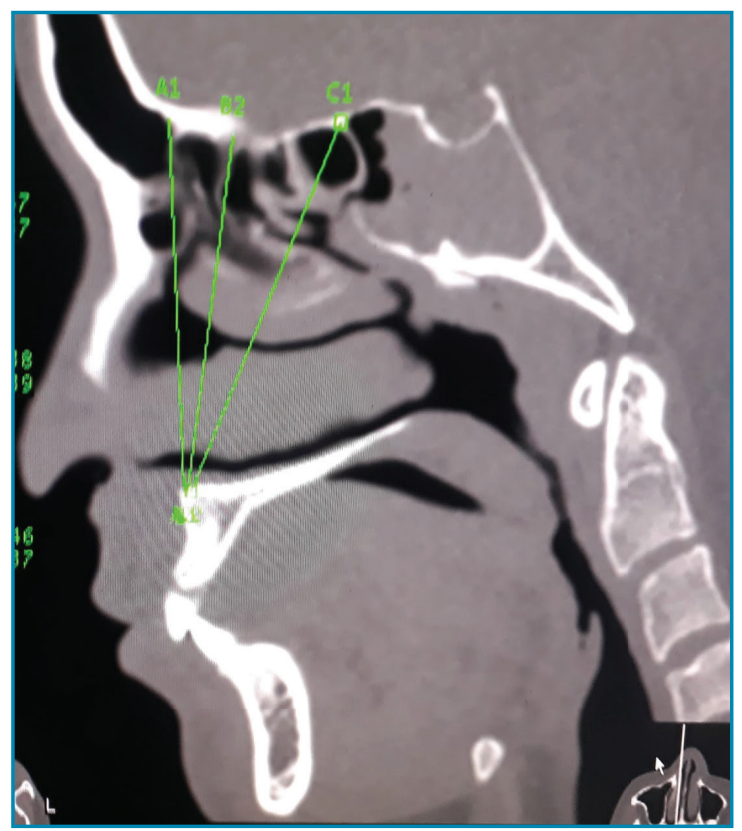

Fig. 4: The measurement between the anterior nasal spine and skull base at the level of Nasofrontal angle, Bullae ethmoidalis and Sphenoethmoid junction on reformatted sagittal image of Paranasal sinuses

with approximately 10-degree Craniocaudal angulation from the midsagittal line, on the right and the left sides separately. All the measurements were performed bilaterally on the screen of the CT console. On coronal reconstruction images, a horizontal line from the most inferior contour of the nasal fossa was drawn. Perpendicular lines from the

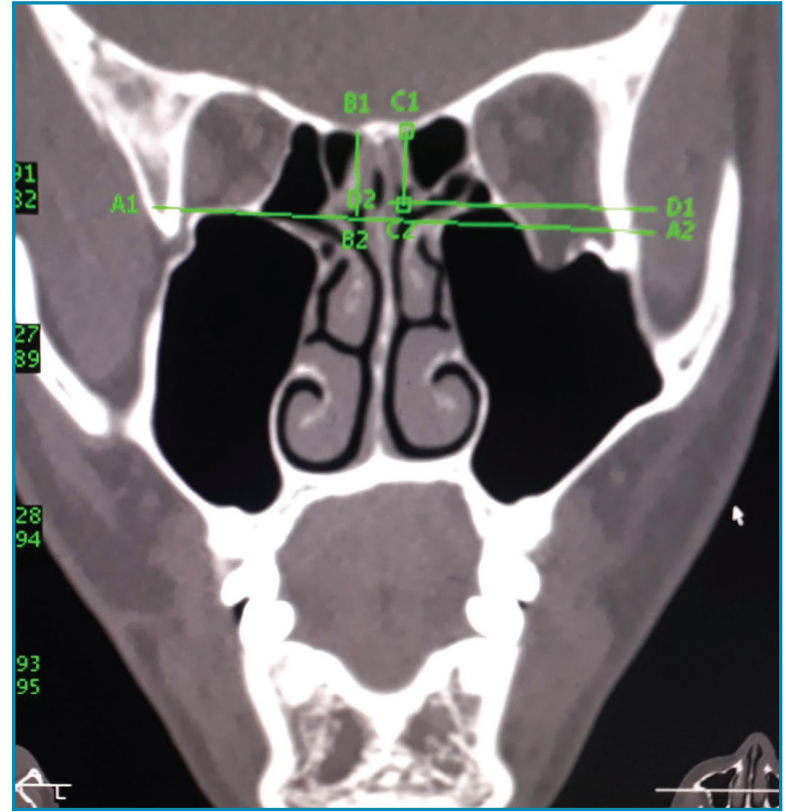

Fig. 5: CT scan Coronal view showing height of plannum from maxillary roof line at spehnoethmoid junction.

ethmoid roof to this horizontal line, at the midlevel between the midsagittal line and lamina papyracea, and also from the cribriform plate to the same horizontal line was drawn. The heights of the ethmoid roof and the cribriform plate were measured at crista galli level at the coronal plane on both right and left sides. (Fig.1) The height of lateral lamella between the medial aspect of the ethmoid roof and the cribriform plate was measured at the level of crista Galli and bulla ethmoidalis (Fig. 2). The Take-off-angle of an ethmoid roof from the horizontal cribriform plate was measured at the level of crista galli. (Fig. 3).

On reconstructed sagittal images, the anterior nasal spine was set as the fixed point, and lines connecting this point with the anterior cranial base at the levels of nasofrontal recess, ethmoid bulla, and the sphenoethmoid junction were drawn $^{5}$ (Fig. 4). On these lines, the distances between the focus point and anterior cranial base were measured and recorded.

In the coronal view, the maxillary roof line parallel to the nasal floor at the maximum height to the maxillary sinus was drawn. Distance from the maxillary roof line to plannum at the anterior wall of sphenoid sinus was measured. Such measurements were performed on both sides (Fig. 5).

Data was recorded in Preformed proforma. All the data were analyzed by SPSS version 26.0. Mean, standard deviation, minimum 
and maximum values were analyzed using Descriptive statistics. The shapiro wilk test was performed to determine the distribution of variables in normal or abnormal patterns. As all our data had a normal distribution pattern, the student paired T-test was applied. When the $\mathrm{p}$-value was less than 0.05 , the difference was considered significant.
RESULTS

This study includes 75 patients, an age range from 18 to 77 years with a mean age of average of $39.8 \pm 14.4$ years. Out of 75 patients, 40(53.5\%) were male and 35(46.7\%) were female. The measurement from the nasal spine to the cribriform plate and ethmoidal

Table 1: Summary of the relationship between nasal floor, anterior skull base a and take of the angle of the cribriform plate

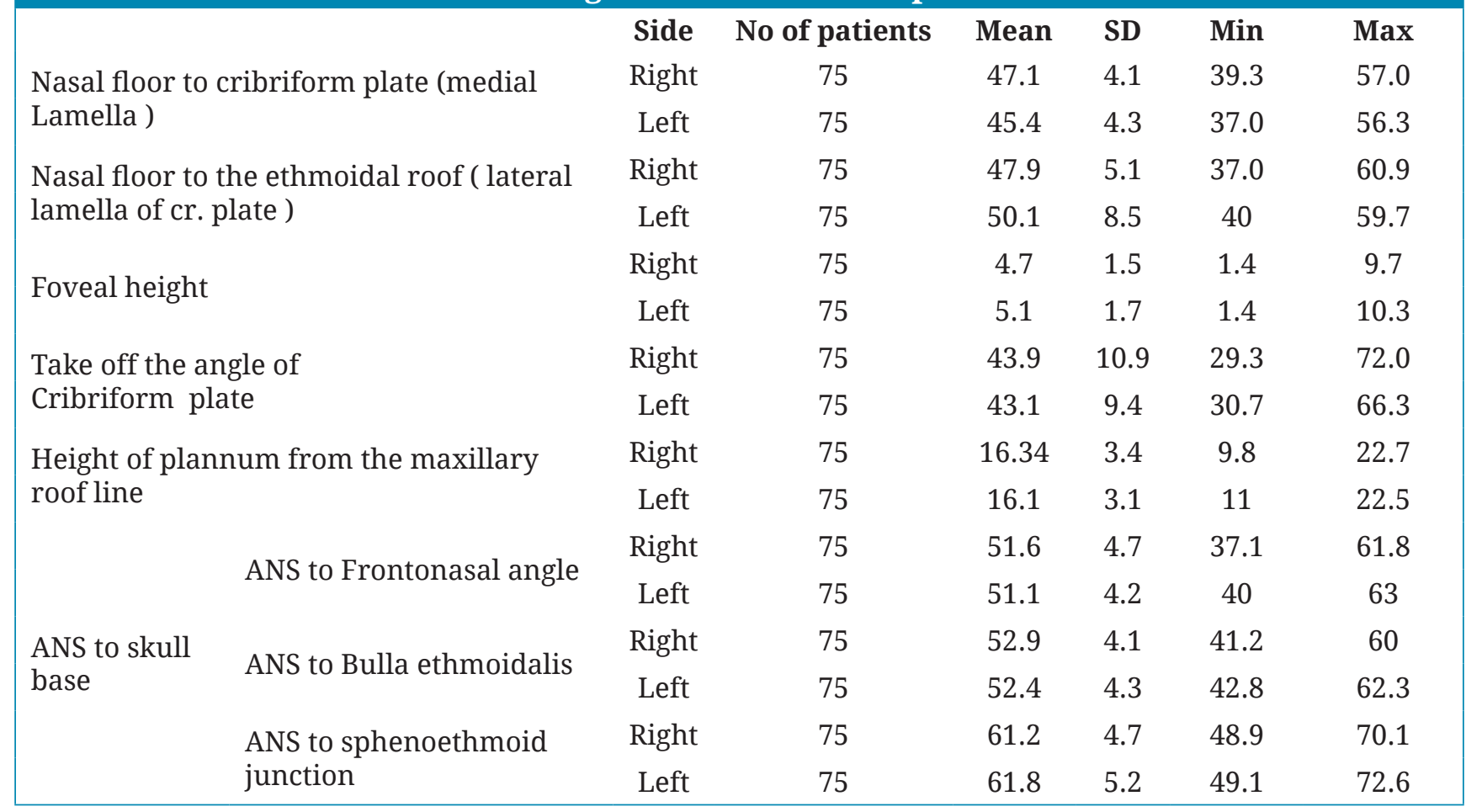

\section{Table 2: Statistical evaluation of normally distributed variables}

\begin{tabular}{|c|c|c|c|c|c|}
\hline \multirow{3}{*}{$\begin{array}{l}\text { Nasal floor to cribriform plate (medial } \\
\text { Lamella) }\end{array}$} & Side & Mean & SD & T value & P-value \\
\hline & Right & 47.1 & 4.1 & \multirow{2}{*}{4.75} & \multirow{2}{*}{0.00} \\
\hline & Left & 45.4 & 4.3 & & \\
\hline \multirow{2}{*}{$\begin{array}{l}\text { Nasal floor to ethmoidal roof ( lateral lamella } \\
\text { of cribriform. Plate) }\end{array}$} & Right & 47.9 & 5.1 & \multirow{2}{*}{-1.28} & \multirow{2}{*}{0.20} \\
\hline & Left & 49.1 & 8.5 & & \\
\hline \multirow{2}{*}{ Foveal height } & Right & 4.7 & 1.5 & \multirow{2}{*}{-2.03} & \multirow{2}{*}{0.04} \\
\hline & Left & 5.1 & 1.7 & & \\
\hline \multirow{2}{*}{ Take off angle of Cribriform plate } & Right & 43.9 & 10.9 & \multirow{2}{*}{0.82} & \multirow{2}{*}{0.41} \\
\hline & Left & 43.1 & 9.4 & & \\
\hline \multirow{2}{*}{ Height of plannum from maxillary roof line } & Right & 16.34 & 3.4 & \multirow{2}{*}{-0.79} & \multirow{2}{*}{0.42} \\
\hline & left & 16.1 & 3.1 & & \\
\hline \multirow{6}{*}{$\begin{array}{l}\text { ANS to skull } \\
\text { base }\end{array}$} & Right & 51.6 & 4.7 & \multirow{2}{*}{1.89} & \multirow[t]{2}{*}{0.06} \\
\hline & left & 51.1 & 4.2 & & \\
\hline & Right & 52.9 & 4.1 & \multirow{2}{*}{1.32} & \multirow{2}{*}{0.19} \\
\hline & left & 52.4 & 4.3 & & \\
\hline & Right & 61.2 & 4.7 & \multirow{2}{*}{1.08} & \multirow{2}{*}{0.28} \\
\hline & left & 61.8 & 5.2 & & \\
\hline
\end{tabular}


roof at the coronal plane on right and left side were mean \pm SD $(47 \pm 4.1,45.3 \pm 4.3,47.9 \pm 5.1$, and $49 \pm 8.5 \mathrm{~mm}$ ) respectively. Mean Take off angle at the cribriform plate was $43.9 \pm 10.9^{\circ}$ on the right side and $43 \pm 9.4^{\circ}$ on the left side. The plannum was found to be $16.3 \pm 3.4$ right side and $16 \pm 3.1 \mathrm{~mm}$ on the left side from the maxillary roof line. The distance from the nasal spine to the skull base (mean \pm SD) at nasofrontal recess, bulla ethmoidalis, and the junction of sphenoethmoid levels at right sides were $51.5 \pm 4.7,52.9 \pm 4.1$ and $61.2 \pm 4.7$ whereas $51 \pm 4.2,52.4 \pm 4.3,61.8 \pm 5.2 \mathrm{~mm}$ were on left side respectively (Table 1 ).

A statistically significant difference was found between right and left-sided height from the nasal spine to cribriform plate, ethmoid roof, and foveal height $(p<0.05)$. The statistical comparison of right- and left-sided measurements have been summarized in Tables 2.

\section{DISCUSSION}

The nasal floor is an important landmark for endoscopic sinus surgery. It's paramount to know different landmarks and distances from nasal floor to skull base to allow safe surgery. The different structure includes uncinate process, cribriform plate. Basal lamella, lamella papyracea, and superior turbinate are the important structure that can focus while doing endoscopic sinus surgery. ${ }^{6}$ However, it is difficult to predict complications after vast knowledge of such structure as soft tissue landmarks may vary. The shape of the anterior cranial base greatly varies among individuals. ${ }^{7}$ Fixed point bony landmarks like the nasal floor, skull base, and maxillary sinus roof should be taken as crucial landmarks while doing the endonasal procedure.

The distance between the nasal floor to the medial lamella of the cribriform plate was 47.1 \pm $4.1 \mathrm{~mm}$ on the right side and slightly lower on the left side. The study by Akiran et $a l^{5}$ found that such height was $53.11 \pm 4.65 \mathrm{~mm}$ which is higher than our mean value. This shows great variability even among the population.

Ethmoid cells reach higher levels than medial lamella of the cribriform plate. Keros classifies the depth of olfactory fossae into three groups and increasing depth is more prone to iatrogenic skull base injuries during endoscopic sinus surgeries. ${ }^{8}$ We have found that the left ethmoid roof and olfactory fossae depth were significantly higher than the right side. The mean olfactory fossae depth was $4.7 \pm 1.5 \mathrm{~mm}$ and $5.1 \pm 1.7 \mathrm{~mm}$ right and left side respectively. The study from south India by Babu et $a l^{9}$ found that the depth of olfactory fossae was $5.26 \pm 1.69 \mathrm{~mm}$ which is not statistically significant between right and left sides. Takeoff-angle is an angle made by lateral lamella of the cribriform plate and a horizontal line passing through CP. We found that the take-off angle was $43.9 \pm 10.9^{\circ}$ (Range $29.3-72^{\circ}$ ) on the right side. It was higher $70.1 \pm 13.1^{\circ}$ (range (28$88^{\circ}$ ) in the study by Abdulla et al. ${ }^{10}$

The height of plannum from the maxillary roof line was $16.3 \pm 3.4 \mathrm{~mm}$, almost equal on both sides in our study which is slightly higher than the study by John et al, who found the mean vertical height of the posterior ethmoid skull base was $14.08 \pm 3.03 \mathrm{~mm} .{ }^{11}$ It was concluded that, as we reach the posterior skull base, it becomes equal height on both sides of the skull base. But the trajectory to the surgical line to the skull base is lower. ${ }^{12}$ So surgeons should be aware of its variation. It was in the range of $9.8 \mathrm{~mm}$ to $22.5 \mathrm{~mm}$ in our study. Large well developed maxillary sinuses will increase the height of posterior ethmoids. We have to keep a safe margin in between skull base and surgical trajectory while doing sphenoid sinus surgery to prevent potential skull base injury.

Sagittal image shows the common important structure in lateral nasal wall and cranial base. The anterior-posterior course of the skull base is sufficiently demonstrated in the sagittal view. Measurement of the nasal spine to frontonasal angle is $51.6 \pm 4.7 \mathrm{~mm}$ on the right side and slightly lower on the left side. The measurement from the anterior nasal spine (ANS) to bulla ethmoidalis increases slightly compared to the frontonasal angle but it steeply raises from bulla ethmoid to sphenoethmoid junction. All our measurement is lower than Study by Akiran et al. ${ }^{5}$ The precision and safety of FESS and skull base surgery have been improved as a result of this measurement's knowledge.

This study provides a detailed analysis of the anterior skull base, allowing the endoscopic surgeon to navigate the surgical plan utilizing Coronal and Sagittal CT scan images, minimizing intraorbital and intracranial complications.

Conflict of interest: None

Source of research fund: None 


\section{REFERENCES}

1. Lee SC and Senior BA. Endoscopic skull base surgery. Clin Exp Otorhinolaryngol 2008; 1: 53.

2. Linsler S, Antes S, Senger S, et al. The use of intraoperative computed tomography navigation in pituitary surgery promises a better intraoperative orientation in special cases. $J$ Neuro Sci Rural Pract 2016; 7: 598.

3. 3.Kim SS, Lee JG, Kim KS et al. Computed tomographic and anatomical analysis of the basal lamellas in the ethmoid sinus. Laryngoscope 2001; 111: 424-9.

4. Davis WE, Templer J, Parsons DS. Anatomy of the paranasal sinuses. Otolaryngologic Clin North Amer 1996; 29: 57-74.

5. Arikan OK, Unal B, Kazkayasi M, et al. The analysis of anterior skull base from two different perspectives: coronal and reconstructed sagittal computed tomography. Rhinol 2005; 43: 115-20.

6. Stammberger H, Posawetz W. Functional endoscopic sinus surgery. Concept, indications and results of the Messerklinger technique. Eur Arch Otorhinolaryngol 1990; 247: 63-76. 1990/01/01. DOI: 10.1007/bf00183169.

7. Lieberman DE, McCarthy RC. The ontogeny of cranial base angulation in humans and chimpanzees and its implications for reconstructing pharyngeal dimensions. J Hum Evol 1999; 36: 487-517. 1999/05/01. DOI: 10.1006/ jhev.1998.0287.

8. V AM, Santosh B. A Study of Clinical Significance of the Depth of Olfactory Fossa in Patients Undergoing Endoscopic Sinus Surgery. Indian J Otolaryngol Head Neck Surg 2017; 69: 514-22. 2017/12/15. DOI: 10.1007/s12070-017-1229-8.

9. Babu AC, Nair M, Kuriakose AM. Olfactory fossa depth: CT analysis of 1200 patients. Indian J Radiol Imaging 2018; 28: 395-400. 2019/01/22. DOI: 10.4103/ijri.IJRI_119_18.

10. Abdullah B, Chew SC, Aziz ME et al. A new radiological classification for the risk assessment of anterior skull base injury in endoscopic sinus surgery. Scientific Reports 2020; 10: 1-7. doi: 10.1038/s41598-020-61610-1

11. Lee JM, Woods T, Grewal A. Preoperative evaluation of the maxillary sinus roof as a guide for posterior ethmoid and sphenoid sinus surgery. J Otolaryngol Head Neck Surg 2012; 41: 361-9. 2012/10/25.

12. Harvey RJ, Shelton W, Timperley D, et al. Using fixed anatomical landmarks in endoscopic skull base surgery. Am J Rhinol Allergy 2010; 24: 301-5. 2010/09/08. DOI: 10.2500/ajra.2010.24.3473. 